\title{
Os pressupostos filosóficos do maquiavelismo e o surgimento da via moderna em política
}

\author{
The philosophical assumptions of the Machiavellianism \\ and the emergence of the modern via in politics
}

* Rodolfo Jacarandá

Resumo: No cenário intelectual do renascimento italiano o pensamento político de Nicolau Maquiavel antecedeu e influenciou grandes inovações que fundaram a modernidade. Um movimento geral de ideias definido no século XVI e XVII pelo conceito de maquiavelismo engendrou mudanças profundas na arquitetura conceitual dos pensadores e articulistas dos assuntos públicos, afetando a obra de grandes filósofos, de Bodin e Lipsius até Hobbes. A partir de pesquisas desenvolvidas no programa de doutorado em filosofia da Unicamp pretendo demonstrar neste trabalho quais foram os pressupostos filosóficos centrais dessa ruptura e como Maquiavel reconstruiu em suas principais obras, O Príncipe e Os discursos sobre a primeira década de Tito Lívio, uma série de conceitos antigos para dar-lhes um sentido completamente novo e radical.

Palavras-chave: Maquiavelismo. Renascimento. Maquiavel. Razão de Estado. Virtude.

Abstract: In the Italian Renaissance intellectual scenario, the political thought of Niccolo Machiavelli preceded and influenced major innovations that founded modernity. A general movement of ideas defined in sixteenth and seventeenth century by the concept of Machiavellianism engendered profound changes in the conceptual architecture of thinkers and writers of public affairs, affecting the work of great philosophers, from Bodin and Lipsius to Hobbes. From research developed in the doctoral program in philosophy at State University of Campinas (UNICAMP) I intend to demonstrate in this work which

Professor Adjunto do Departamento de Filosofia da Universidade Federal de Rondônia. <rfjacaranda@uol.com.br> 
were the core philosophical assumptions of this revolution and how Machiavelli rebuilt in his major works, The Prince and Discourses on the first decade of Livy, a series of ancient concepts to give them a completely new and radical direction.

Keywords: Machiavellianism. Renaissance. Machiavelli. Reason of State. Virtue.

\section{Considerações iniciais: o maquiavelismo e a obra de Maquiavel.}

$\mathrm{O}$ pensamento político de Nicolau Maquiavel teve uma importância fundamental para as rupturas que deram origem à modernidade política. Embora exista elevado número de debates acerca dos principais aspectos do pensamento maquiaveliano envolvidos na transição da idade média para o renascimento, e desse para a modernidade propriamente dita, creio que uma distinção é bastante importante e tem sido sistematicamente ignorada: uma tarefa é a de avaliar e reconstruir o significado filosófico dos postulados básicos da obra de Maquiavel; outra é analisar a forma como seus textos foram lidos e debatidos por seus contemporâneos, pensadores ou agentes políticos. Após, resta um importante problema, portanto, a ser resolvido: definir, o mais corretamente possível, a equivalência entre a repercussão de sua obra e seus textos propriamente ditos. A intensidade com que as propostas de Maquiavel em O Príncipe circularam deu origem a um movimento geral de ideias denominado maquiavelismo ${ }^{1}$. Essas ideias traduziam, quase sempre, o primado da

1 Conceito considerado por muitos autores sinônimo de razão de Estado o maquiavelismo foi objeto de amplos estudos ao longo do século XX, alguns deles renovados pelas pesquisas de Michel Foucault no Collège de France, na década de 1970. Entre os italianos, um estudo clássico sobre o tema é MATTEI, R. De. Il problema della "ragion di Stato" nell'Età della controriforma. Milano - Napoli: Riccardo Ricciardi Editore, 1979. Na Alemanha o livro de maior repercussão foi o hoje clássico Die Idee der Staatsräson in der modernen Geschichte, de Fridrich Meinecke. Cf. MEINECKE, F. L'idée de la raison d'État dans l'histoire des temps modernes. Traduit de l'allemand par Maurice Chevallier. Geneva: DROZ, 1973. Aluno de Foucault, Michel de Senellart publicou vários trabalhos entre os anos 1980 e 2000, cf. SENELLART, M. Machiavélisme et raison d'État -XII $-X V I I I^{e}$ siècle. Paris: Presses Universitaire de France, 1989. Cf. LAZZERI, C. ; REYNIÉ, D. (Org.). La raison d'État : politique et rationalité. Paris: Presses Universitaires de France, 1992; THUAU, E. Raison d'État et pensée politique à l'époque de Richelieu . Paris: Albin Michel, [1966] 2000. Mas o maior empreendimento para documentar o maquiavelismo foi registrado pelo grupo Archivio della Ragion di Stato, comandado por Gianfranco Borreli e Silvio Suppa, dentre outros. Cf. BORRELI, G. Ragion di Stato e leviatano - conservazione e scambio alle origini della modernità politica. Bolonha: Il Mulino, 1993; BORRELI, G. [A cura di]. Prudenza civile, bene comune, guerra giusta. Percorsi della ragion di Stato tra seicento e settecento. Teoria e storia della ragion di Stato. Quaderno 1. Napoli: Archivio della Ragion di Stato - Adarte, 1999. BORRELI, G. [A cura di]. Machiavelli e la cultura politica del meridione d'Italia. Teoria e storia della ragion di Stato. Quaderno 2. Napoli: Archivio della Ragion di Stato - Adarte, 2001.; e SUPPA, S. [A cura di]. Tacito e tacitism in Italia da Machiavelli a Vico. Teoria e storia della ragion di Stato. Quaderno 3. Napoli: Archivio della Ragion di Stato - Adarte, 2003. 
supremacia do poder político, público, sobre a moralidade privada dos indivíduos. Na maior parte dos casos, o maquiavelismo, em sua origem, dizia respeito a manipular conceitos muito explorados por antipatizantes de Maquiavel que estavam concentrados em preservar certa ordem de coisas concernentes à jurisdição teológica e às estruturas feudais de poder em mutação no fim do século XV. Apesar desse compasso ajustado entre antimaquiavelistas multipartidários em torno de um conservadorismo militante, algumas reações inovadoras ao pensamento de Maquiavel foram as grandes responsáveis pela sedimentação do maquiavelismo como um dos fundamentos da estatalidade moderna, concebida por pensadores e homens políticos do século XVI e XVII.

Mas, de que forma esses conceitos eminentemente já estavam sendo tratados na obra maquiaveliana? Qual a relação entre Maquiavel e seus pares - muitos deles reformistas ainda presos a tradições antigas? Para um intelectual do governo que jamais usou o termo "política"2 quais eram as principais preocupações morais e sociais com que se debatia para propor de forma inédita postulados tão incisivos acerca da condução dos assuntos do poder?

Com a finalidade de esclarecer algumas dessas questões vou apresentar um (I) resumo do cenário intelectual precedente ao renascimento italiano para, após, demonstrar como Maquiavel (II) reformulou antigas noções acerca da virtude e suas implicações sociais. A seguir, demonstrarei, usando análises de pesquisadores como J. G. A. Pocock, Maurizio Viroli e Harvey Mansfield, de que forma essa renovação engendrou o caminho para que a (III) utilização de conceitos como necessidade e inovação pudessem servir de mecanismo de (IV) justificação para a disposição de reservas fundadoras de poder numa configuração jamais vista antes ensejando o maquiavelismo e os pressupostos para a definição conceitual de estado, ainda na segunda metade do século XVI.

\section{O contexto intelectual da revolução maquiaveliana}

O processo histórico do renascimento italiano nos séculos XV e XVI revitalizou crenças antigas sobre as capacidades individuais do homem. Essas crenças serviram de base para ideias revolucionárias que, progressivamente, levaram ao colapso das estruturas medievais. Dentre as questões mais importantes para o pensamento dos humanistas medievais estavam as crenças de que o mais alto nível de excelência

2 WHITFIELD. J. H. "The Politics of Machiavelli", The Modern Language Review, 50(4). (Oct., 1955), p. 433-443. Não há aparições da palavra politica (ou derivados) em O Príncipe, e apenas sete recorrências nos Discorsi, todas na forma adjetivada de vivere politico, geralmente opondo vida civil à religiosa. 
moral poderia ser atingido pelo esforço humano e de que isso seria possível por meio da educação ${ }^{3}$. Leitores ávidos de Marco Túlio Cícero e Sêneca, como Dante e Francesco Petrarca, subverteram a obediência irrestrita à ideia de fragilidade humana proveniente da teologia cristã, construindo uma via humanista para a busca do aperfeiçoamento individual. Uma extensa série de textos discutindo a aquisição da virtus pelo homem foi produzida por autores como Pico della Mirandola, Pier Paolo Vergerio, Bartolomeu della Fonte, Giannozzo Manetti, Salutati, Bruni e Alberti, ajudando a consolidar a impressão de que havia mesmo uma importante ruptura histórica sendo preparada.

A tese petrarquiana de que o próprio homem é a única criatura capaz de "vencer qualquer obstáculo" e "refazer o mundo social para adequá-lo aos seus desejos", controlando seu destino, propunha, de forma acentuada, uma mudança na maneira de o homem se relacionar com seu ambiente, usando suas forças para alterá-lo, fortalecendo a crença de que a virtus poderia sim vencer a fortuna (virtus vince fortuna). Contudo, apesar do caráter antimedieval dos postulados petrarquianos, a ideia clássica de virtus em que estavam fundamentados era, ainda, vigorosamente influenciada pela doutrina cristã segundo a qual a virtus evita os vícios porque estes são por natureza maus, e que se deve buscar as virtudes porque são naturalmente boas.

A presença forte e definidora do papel da natureza na vida humana explica por que o mais polêmico dos autores do renascimento, o florentino Nicolau Maquiavel, ao escrever ainda está bastante tomado pela perspectiva de uma relação intrincada e indissolúvel entre a fatalidade do destino e as contas acerca da potencial liberdade de ação do homem .

Para Pierre Mesnard os fundamentos metafísicos do sistema maquiaveliano revelam um pensador compenetrado no misticismo paduano e de Averróes, algo que se refletia no seu extremo pessimismo ${ }^{5}$. Essa percepção das coisas derivava da concepção de um mundo criado com tal massa completa que, através da história, apenas muda de mãos,

3 SKINNER, Q. As fundações do pensamento político moderno. São Paulo: Martins fontes, 1996. p. 111-112.

4 Com relação às obras de Maquiavel citadas neste artigo: MAQUIAVEL, N. Il Principe (De principatibus) Edizione a cura de Luigi Firpo. Torino: Einaudi Editore, 1972; Discorsi sopra la prima deca de Tito Livio. Tutte le Opere de Niccolò Machiavelli. A cura de Mario Martelli. Firenze: Sansoni Editore, 1971. Uso as seguintes traduções para o português: MAQUIAVEL, N. O Príncipe. Tradução de Maria Júlia Goldwasser. São Paulo: Martins Fontes, 1996. MAQUIAVEL, N. Discursos sobre a primeira década de Tito Lívio. Tradução MF. São Paulo: Martins Fontes, 2007. Para referências rápidas em notas ou no corpo do texto usarei o termo Discursos ou Discorsi para me referir ao segundo livro, seguido do número do livro e do capítulo - em ambos os casos fazendo referência às traduções brasileiras citadas anteriormente.

5 MESNARD, P. L'essor de la philosophie politique au XVI ${ }^{e}$ siècle. Troisième édition. Paris: Vrin, 1977. p. 20. 
não existindo nem progresso nem novidade real no mundo natural; a crença nos prodígios, muito comum à época, é, no entanto, contra o progresso humano, descortinando uma desesperança cujo mais exato reflexo é a natureza completamente instável da existência. $\mathrm{E}$ se a instabilidade é o destino da humanidade, como remediá-la? Essa sempre foi a questão chave do pensamento de Nicolau Maquiavel . Isso porque, apesar de seu pessimismo, Maquiavel defendia que entre os caprichos da fortuna e a liberdade do homem cabia a este último negociar bem a sua parcela de capacidade de ação.

De modo geral as reflexões de Maquiavel o levaram a concluir que a natureza tem seu curso, mas que é possível lutar para oferecer-lhe resistência. Acima do homem comum, esse é o papel do governante, que deve conter os súditos e, compreendendo a fortuna e aprendendo a lidar com ela, instaurar um controle firme sobre a contingência. Nada melhor para entender a fortuna do que estudá-la e também os seus efeitos sobre a civilização humana. Eis o que leva Maquiavel a criar um estudo experimental do governo da fortuna, usando a história como laboratório de experiências onde o governante deve analisar o passado e procurar, no que lhe couber, conduzir seu destino.

O fato é que a instabilidade política da época de Maquiavel não lhe deixava muitas opções, sobretudo porque como homem de ação era pouco inclinado a concessões idealizadoras, preocupado que estava com a dinâmica objetiva do poder ${ }^{6}$. Nos termos propostos por Grant Mindle, tal senso de objetividade era voltado, contudo, à avaliação das relações de força convergentes para os negócios ao seu redor, mais do que à tarefa de elaborar um sistema científico sobre a política, num sentido que propriamente se poderia chamar de moderno ${ }^{7}$. O substrato real do sistema maquiaveliano, descrito por Mesnard, era um cenário típico onde o embate de forças desgastava, enfraquecia e destruía as relações sociais constituídas, cada vez mais rapidamente. Exemplo contemporâneo a Maquiavel foi o principado de Urbino, que durante sua vida viu mais de dez governos diferentes. E mesmo Florença, sua cidade, passou do regime republicano com instituições fundamentais para um regime de autoridade pessoal, hereditário e aristocrático (os Médici ), e deste para o regime legal de Soderini até o regime sentimental e demagógico de Savonarola . Pelas contas de Mesnard, em menos de 40 anos a constituição foi seis vezes reformada: 1490, 1494, 1495, 1502,

6 QUARTIM DE MORAES, J. A justificação do tiranicídio no pensamento protoliberal de Juan de Mariana. Coleção Primeira Versão, IFCH/UNICAMP. Campinas: IFCH/UNICAMP, 1993. p. 12.

7 MINDLE, Grant B. "Machiavelli's Realism”, The Review of Politics, 47(2) (Apr. 1985), p. 212-230. 
1512, 1527, fora os complôs, golpes, exílios, banimentos, etc., tornando mais sensível a atmosfera de insegurança ${ }^{8}$.

Aprender a compreender as circunstâncias e reagir o mais imediatamente possível a elas era uma exigência para os homens políticos. O historiador das ideias políticas Quentin Skinner é enfático sobre esse ponto ao insistir que o cerne da compreensão de Maquiavel sobre a liderança política foi sem dúvida a constatação da debilidade básica dos governantes de seu tempo por serem inoperantes diante das mudanças ${ }^{9}$. Para Maquiavel o governo devia estar sempre preparado para modificar suas ações assim que fosse exigido pelas circunstâncias. Embora a luta contra a instabilidade da fortuna indicasse a virtù dos maiores líderes, era preciso saber reconhecer quando não havia condições de dobrar o destino diante das dificuldades apresentadas. Neste caso, caberia ao governante saber quando ser duro e controlador, e quando se abster e mudar os rumos. Para descrever a flexibilidade perante a necessidade de tomar decisões firmes em momentos distintos Maquiavel se utilizou de uma metáfora antiga, bem conhecida entre autores políticos, sobrepondo, alternadamente a forma de agir de uma raposa e a de um leão, representando o dualismo próprio e permanente às ações políticas ${ }^{10}$.

Maquiavel provavelmente utilizou o símbolo da relação entre o leão e raposa (O Príncipe, XVIII) em referência ao uso que fez dele Cícero no De Officis, mas a origem da metáfora é um texto de Plutarco sobre o general espartano Lisandro, morto em 395 a. C., que teria justificado suas ações políticas com a seguinte máxima: onde a pele do leão não é o bastante é necessário vestir a da raposa ${ }^{11}$. Plutarco coloca Lisandro no

8 Importantes para a compreensão do cenário político da península italiana são os estudos de Hans Baron. Cf. BARON, H. "A Struggle for Liberty in the Renaissance: Florence, Venice, and Milan in the Early Quattrocento (Part one)". The American Historical Review, 58(2) (Jan. 1953), p. 265-289; e BARON, H. "A Struggle for Liberty in the Renaissance: Florence, Venice, and Milan in the Early Quattrocento (Part two)", The American Historical Review, 58(3) (Apr. 1953), p. 544-570.

9 SKINNER, Q. Maquiavel. Tradução de Maria Lúcia Montes. São Paulo: Ed. Brasiliense, 1988. p. 32. Para uma biografia intelectual mais detalhista de Maquiavel cf.: DIONISOTTI, Carlo. Machiavelleire. Torino: Einaudi Editore, 1980.

10 Maquiavel discute o uso da metáfora numa carta a Vettori, de 20 de agosto de 1513, ao tempo em que estava escrevendo O Príncipe . Cf.: RIDOLFI, Roberto. Biografia de Nicolau Maquiavel. São Paulo: Musa Editora, 2003. p. 170-171. Para J. G. A. Pocock o leão serve de padrão para a ideia de virtude, ou seja, o poder de dominar as contingências, enquanto a raposa é a imagem da prudência, símbolo do poder de manipular a virtude. Cf. POCOCK, J. G. A. "Machiavelli in the Liberal Cosmos". Political Theory, 13(4) (Nov. 1985), p. 559-574, p. 562. Para um estudo que defende uma relação mais amigável entre Cícero e Maquiavel cf.: COLISH, M. "Cicero's De Officiis and Machiavelli's Prince", Sixteenth Century Journal, Central Renaissance Conference, 9(4) (Winter, 1978), p. 80-93.

11 "Laddove la pelle del leone non è sufficiente, bisogna indossare la pelliccia della volpe". STOLLEIS, M. Stato e ragion di stato nella prima età moderna. Bolonha: Il Mulino, 1998. p. 13. (Collezione di testi e di studi). 
mesmo plano do ditador romano Sila, acusado de possuir uma astúcia volpina que lhe permitia agir segundo o princípio de que o astuto e o forte devem se ajudar, quando um ou outro não for o bastante. O historiador grego estava preocupado em definir se a justiça ou a religião subordinam a política, ou se esta última aceita o engodo e a simulação da verdade caso o fim em vista seja considerado lícito - é um problema parecido que ressurgirá na idade média dissolvendo a unidade medieval da religião e da ordem civil feudal.

A herança clássica dos historiadores romanos, contudo, aparecia, para os olhos dos renascentistas, sobrecarregada de advertências respeitosas quanto aos poderes da fortuna, nem sempre vista como deusa má. Temer e respeitá-la era questão de sabedoria, sobretudo porque os favores da fortuna eram almejados por todos: a honra, a riqueza, a influência, o poder e a glória. A melhor forma de alcançar tais objetivos era encontrar meios de ser favorecido por ela. Aqui o conceito de virtù e seus derivativos exercem função especial. Skinner se inclina por uma tradução mais próxima da ideia de virilidade, embora seja corrente compreendê-la em relação a cada atividade específica - a virtù é um atributo dos homens viris ${ }^{12}$.

Para entender como Maquiavel altera o sentido da proposição clássica sobre os valores próprios ao homem político J. G. A. Pocock aprofundou a investigação de uma relação entre fortuna e virtù que admitia a importância da história e de seus significados distintos para o cristianismo e a antiguidade romana. Para o pesquisador de Cambridge, nem gregos nem romanos possuíam muitos motivos para esperar algo novo do futuro para a humanidade ${ }^{13}$. Ao reconstituir o momento histórico e as maiores influências intelectuais consideradas por Maquiavel a tese geral de Pocock envolveu considerar que houve uma ruptura, moderna por excelência, na política com a assunção, na península italiana, de uma forma republicana de governo que não se identificava com seus pressupostos medievais. Essa ruptura somente teria sido possível pela materialização do projeto de uma sociedade fundamentada no pressuposto aristotélico de que a natureza do homem é política e deve ser trabalhada para lutar contra a irracionalidade e a insegurança do mundo. Seguindo a análise de Pocock, o monoteísmo salvacionista cristão reorganizou e transformou a temporalidade em função da esperança da eternidade. A vida do homem era interpretada como uma série de eventos

12 SKINNER, Q. Maquiavel, op. cit., p. 46. Cf. GILBERT, Felix. "On Machiavelli's Idea of Virtu". Renaissance News, 4(4) (Winter, 1951).

13 POCOCK, J.G.A. The Machiavellian moment - Florentine Political thought and the Atlantic republican tradition. Princeton and Oxford: Princeton University Press, [1975] 2003. p. 31. Intr., p. vii e viii. 
temporais e atemporais, que o vinculavam não só à formação da própria humanidade, mas do planeta como um todo, do nascimento até a morte. Sua vida recebia significado por meio da atemporalidade que precedia sua existência e daquela que deverá advir após sua morte. Em suma, enfatiza Pocock, a história, no cristianismo, adquire significado por meio da subordinação à escatologia.

A vida humana, na linguagem da patrística, seria observada a partir dos atos que a desprenderam de Deus e, enquanto durar a existência, podem levá-lo de volta até Ele, além daquelas ações que constituem um mero viver no mundo, pura sobrevivência. A primeira sequência parte da difícil definição de um horizonte presente e vive na espera da realização do programa da salvação e representa a vida religiosa. A segunda resume os atos perceptíveis pelo homem nos intervalos de tempo onde a pressão pela reunião com Deus é menos atual e se dá na indeterminação que finda por ser tomada como períodos paralelos à vida religiosa - esse segundo tipo de vida era saeculum, em oposição à vida sacra.

A grande questão a ser pensada no horizonte medieval é a maneira como a vida sacra e a vida secular passam a se organizar numa convivência temporalmente equivalente. Inicialmente, não havia como excluir a pressuposição de que uma intenção divina regulava os assuntos da vida civil. Mas Agostinho rejeitou essa concepção que atrelava a salvação à história secular para negar especialmente o fato de que o cristão poderia se tornar cidadão de determinada comunidade política com o objetivo de alcançar a salvação. A proposta de Agostinho era separar escatologia e história. A salvação consistiria numa associação à civitas Dei, uma sociedade em comunhão atemporal com Deus, uma sociedade que está ela mesma fora do tempo. A civitas terrena não pode ser identificada com a civitas $D e i^{14}$. Nenhum império secular pode representar os ideais de redenção que simbolizam os compromissos cristãos, nem modelo de vida civil algum pode ser propenso a resumir esse fim ${ }^{15}$.

Assim, o presente histórico secular pertence, para a vida do homem, a um drama escatológico não revelado. Foi justamente essa visão agostiniana que Boécio pretendeu superar rearticulando em conceitos clássicos o dualismo rigoroso de Agostinho, apostando que o homem de virtude deve agir na civitas terrena mesmo que esteja fadado a se ver às voltas com as ilusões que lhe são peculiares. Agir é expor-se ao mundo de mutabilidade e inseguranças que caracterizam a história secular, e não deixa de ser significativo que Boécio utilize o conceito de fortuna

14 POCOCK. J. G. A. The Machiavellian moment. op. cit., p. 34.

15 Cf. SCATTOLA, M. Teologia politica. Collezione Lessico della politica. Bologna: Il Mulino, 2007. 
para representar essa dimensão histórica. Fortuna é um termo retirado do ethos romano, republicano e imperial, mais próximo do sentido de um indivíduo de sorte (felix ou faustus em latim) do que de algo inesperado ou casual. Embora a "sorte" induza a reflexão sobre algum tipo de qualidade especial que um indivíduo pareça possuir que lhe permita controlar as circunstâncias, é um de seus elementos constitutivos o caráter impreciso e não controlável que rege sua dedicação aos homens. $\mathrm{O}$ conjunto de qualidades que alguém deve portar para estar disposto em face da fortuna é aquilo que os romanos chamavam de virtus, termo cuja complexidade Pocock reproduz minuciosamente como uma virtude característica da relação do homem com a sua história comunitária, social, política. No século XV e XVI o termo virtus era frequentemente usado em oposição à fortuna em imagens sexuais, relatando o imperativo do domínio do masculino, ativo e inteligente, sobre o feminino, passivo e imprevisível, que se submete à força e coragem daquele, ou o trai, vingativamente, em razão de sua fraqueza.

A carga de significados associados à palavra virtus reporta aos sentimentos romanos de virilidade cívica. Proveniente da linguagem de uma classe política e militar, virtus - vir significava homem - foi associada ao conceito grego de areté, sendo refinada e transformada num rol de qualidades individuais que ligam o homem aos seus deveres de cidadão, de bondade e responsabilidade moral que o tornam, na cidade ou no cosmos, aquilo que ele deve ser. Rapidamente, o conceito anexou o rol de obrigações morais que diziam respeito à vida cristã e seu significado original esteve praticamente perdido até que o debate entre virtus e fortuna fosse restaurado por Boécio . Mas Boécio, e de resto toda a tradição pós-agostiniana, insiste Pocock, manteve o assunto preso aos limites da natureza privada da salvação individual.

A idade média e a própria tradição agostiniana criaram assim um sistema de pensamento que funcionava em termos teológicos e filosóficos de modo estático, mas que era periodicamente afrontado pelos ideais de pertença a determinada comunidade política e pelas consequentes aspirações que denotavam o envolvimento com as perspectivas mundanas. Mas a tradição medieval não permitia que um aparato racional acumulado pela experiência política das cidades europeias se desenvolvesse para permitir maior participação dos cidadãos nas discussões sobre os destinos da comunidade em face das agressões do tempo e das circunstâncias. Somente uma teoria do conhecimento nova poderia propor as condições favoráveis para que decisões coletivas sobre eventos públicos pudessem ser tomadas por cidadãos conscientes do controle de seu próprio destino. O que Pocock defende é que a história do pensamento político florentino deve ser analisada como a história 
da quebra e emancipação parcial dessas limitações medievais - e que Maquiavel foi o principal ator nesse processo.

Os primeiros grandes pensadores políticos italianos do século XIV ainda estavam dispostos, porém, a pensar sobre a cidadania republicana no contexto de uma ordem e autoridade universal, que podia ser expressa de forma hierárquica e apocalíptica, ligando a cidade ao Sacro-Império, aos deveres para com a religião e o Papado, e mesmo ao fim dos tempos com o juízo final. Mas, o esforço por erigir um sistema moral institucionalizado em uma configuração histórica e finita (a comunidade política) seria visto pelo expectador medieval como uma arriscada submissão do destino coletivo às misericórdias da fortuna. O que os humanistas cívicos florentinos fizeram foi encontrar uma forma de abrir mão dos modos tradicionais de organização política atemporais para tentar realizar os valores universais de que estavam imbuídos em repúblicas particulares, finitas e historicamente situadas. Os mecanismos utilizados pelos humanistas cívicos para cumprir essa tarefa causaram imenso impacto no fim do quatrocentos e começo do quinhentos, e dentre esses mecanismos poucos repercutiram tanto quanto aqueles defendidos por Maquiavel no livro O Príncipe .

De fato, Maquiavel foi um típico humanista florentino, no entanto, bastante crítico do humanismo moralista, especialmente aquele sob as influências de autores como Cícero . Foi um legítimo filho do humanismo, mas filho pródigo sem retorno dos humanistas ${ }^{16}$.

Maquiavel rompeu com a tradição moralista medieval e ainda levou a consequências radicais o humanismo de seus contemporâneos, mas o caminho para entender essa inflexão intelectual poderosa é tortuoso e de difícil reconstituição. Seguramente, esse caminho aponta para a filosofia civil de Aristóteles ${ }^{17}$ e a então recente tradição renascentista, havendo traços relacionados a vários autores quanto às preocupações quatrocentistas e quinhentistas para justificar e legitimar os poderes dos príncipes e governantes de um modo geral.

Repúblicas e principados conviviam de modo inseguro na península italiana próximos a grandes reinos, ao Sacro Império e ao Papado (que se comportava como um principado), havendo enorme demanda por

16 RIDOLFI, R. Biografia de Nicolau Maquiavel. op. cit., p. 30.

17 Yves Charles Zarka define três razões básicas para que o aristotelismo interessasse aos teóricos renascentistas: (i) Aristóteles toma a realidade política em sua particularidade e contingência próprias; (ii) ele trata de definir os meios de conservar as constituições, definindo as causas internas e externas de suas mudanças e salvaguardas; (iii) e ele desenvolve uma teoria das virtudes dos governantes, tema fundamental para a época. ZARKA, Y. C. "Crise et réappropriation discursive: l'usage de l'aristotélisme dans les traités de la raison d'État", p. 315. In: BALDINI, Enzo [org]. Aristotelismo politico e ragion di Stato. Atti del convegno internazionale di Torino, 11-13 febbraio 1993. Firenze: Leo S. Olschki Editore, 1995. 
conquistas e processos de dominação legítima dos respectivos governos. Essa confusão foi encarada por Maquiavel como verdadeira marca distintiva da política de sua época. Tanto que O Príncipe não é dedicado a todo tipo de príncipe, mas somente àquele que chegou ao comando do principado há pouco tempo, e que não o ganhou por herança dinástica - os principados novos ${ }^{18}$, justamente o caso dos Médici em Florença em 1513.

Embora alguns indícios marcantes da literatura humanista possam ser encontrados em O Príncipe, como o problema da diferença entre o príncipe e os cidadãos "privados", e a concepção do príncipe como uma força política criativa ${ }^{19}$, Maquiavel não se associou por completo à tradição humanista, chegando mesmo a refutar seus predecessores ${ }^{20}$. Além disso, não há muitas dúvidas de que Maquiavel desafia as conclusões moralistas de Cícero e se opõe à tradição política agostiniana e aquiniana. Apesar do humanismo latente no último capítulo de O Príncipe, com forte apelo nacionalista ${ }^{21}$ à unificação da Itália, a integração entre Maquiavel e seus pares não é tão profunda. Mas o que importa nesse debate é compreender de que forma sua metodologia de trabalho permite identificar a existência de um liame entre os mecanismos radicais propostos para o controle do poder e uma concepção teórica geral da política em seus escritos; além de auxiliar a entender de que forma essa articulação permite divisar um pensador consciente das transformações em movimento no começo do século XVI. Em resumo, trata-se de divisar as condições que o levaram a transformar a reflexão política independente em prioridade num ambiente ainda pouco propício a inovações.

O moralismo religioso e o rígido controle feudal exercido pelas relações nobiliárquicas impediam não apenas a execução e a manutenção de projetos de independência como aqueles que cidades como Florença se esforçavam por levar adiante entre o fim do século XV e o começo do século XVI, mas também obstruíam a própria renovação e o aprimoramento desses projetos - assim como atrapalhavam a circulação e a propagação de novas ideias entre os cidadãos e seus governantes.

\section{A virtude dos antigos e a virtude dos modernos}

A primeira linha argumentativa para compreender como Maquiavel parece estar diante da tradição medieval para se opor a ela é o fato de que

${ }_{18}$ MAQUIAVEL, N. O Príncipe, cap. II.

19 GILBERT, F. "The humanist conception of the Prince and The Prince of Machiavelli". The Journal of Modern History, 11(4) (Dec. 1939), p. 449-483. p. 479.

20 Maquiavel, O Príncipe, cap. XV.

${ }^{21}$ Cf. GILBERT, F. “The Concept of Nationalism in Machiavelli's Prince". Studies in the renaissance [Published by Renaissance Society of America], 1 (1954), p. 38-48. 
o livro O Príncipe foi escrito para um príncipe novo, recém empossado em seu trono, tendo conquistado, e não herdado ou recebido por transmissão jurídica, seu principado. A segunda indicação é o fato de o texto do livro voltar-se exclusivamente para as funções governamentais sem privilegiar os impactos na cidadania desse novo governo. Esse segundo aspecto (a cidadania) foi amplamente estudado nos Discursos, declaradamente um trabalho sobre as repúblicas. O príncipe, na visão republicana de Pocock e compartilhada por alguns de seus contemporâneos como Skinner, Viroli e Gisela Bock ${ }^{22}$, é um estudo analítico sobre a inovação e suas consequências. Maquiavel abandona o ponto de vista do ideólogo ottimate e se debruça sobre a incapacidade de uma organização social fragmentária e decadente exercer controle sobre os rigores da fortuna . A política seria assim a arte de impor ordem sobre a fortuna, sobre a irascível contingência que abate a comunidade em razão de seus próprios erros. O que Maquiavel propõe em Il Principe é uma inversão da questão romana clássica ao indagar se há alguma virtù específica que possa auxiliar um governante isolado de sua comunidade moral que o ajude a dominar a fortuna, e quais seriam as qualidades morais específicas de um governante nessa situação de isolamento necessário provocado por sua condição de recém-empossado - ato este que é essencialmente político e não jurídico. Para entender melhor a gênese das preocupações de Maquiavel nesse desafio Harvey C. Mansfield ${ }^{23}$ afirma que Maquiavel conduziu um confronto entre as virtudes cívicas antigas e modernas com consequências que resultaram no fim de uma era e no começo de outra.

Em termos metodológicos nem Mansfield, nem Pocock, Skinner ou mesmo Hans Baron reconhecem o abismo conceitual defendido por muitos entre O Príncipe e os Discursos, apesar de divergirem pontualmente sobre a inspiração para o modelo de republicanismo adotado pelo florentino. Limito-me a observar que os Discorsi e O Príncipe foram elaborados na mesma época, embora os Discorsi fossem o produto de anotações feitas por um longo período, enquanto O Príncipe parece mesmo ter sido escrito de um rompante no seu exílio em 1513 em Sant'Andrea in Percussina - Ridolfi chega ao ponto de defender que o livro seria uma espécie de extrato dos Discorsi ${ }^{24}$.

Hans Baron contrapõe essa ideia por meio de uma análise minuciosa das cartas de Maquiavel e da sequência do texto dos dois livros. Para ele, é bastante improvável que os Discorsi tenham começado a ser redigidos em 1513, e as referências que constam em O Príncípe provavelmente

${ }_{22}$ BOCK, G.; SKINNER, Q.; VIROLI, M. Machiavelli and republicanism. Cambridge University Press, 1993.

${ }^{23}$ MANSFIELD, H. The Machiavelli's virtue. Chicago: The Chicago University Press, 1996.

24 VIROLI, M. Biografia de Nicolau Maquiavel. op. cit., p. 173. 
foram colocadas depois que o texto estava pronto e tinha começado a circular ${ }^{25}$. Embora os dois livros não tivessem sido escritos juntos, alega Baron, não haveria rupturas entre eles, mas uma clara distinção entre dois propósitos, já que O Príncipe atendia a objetivos imediatos com a retomada do comando de Florença pelos Médici, e os Discorsi ainda seriam meditados e debatidos nas reuniões dos Orti Oricellari durante cinco anos. De toda sorte, a própria crença de que O Príncipe foi escrito num impulso também é contestada por Baron, alegando a longa experiência acumulada por Maquiavel em 14 anos de diplomacia - mas isso não inibe o argumento de Ridolfi quanto ao tempo que Maquiavel levou para colocar o texto no papel ${ }^{26}$.

Skinner, por sua vez, defende que os Discorsi são outra radicalização do pensamento de Maquiavel, mas não uma contradição. Se em O Príncipe a prioridade era a segurança, aqui o tema principal seria a liberdade ${ }^{27}$. Mas liberdade que significa, antes de tudo, independência em face de agressões externas e em face da ameaça de tirania ${ }^{28}$. Para Mesnard, não há diferença obtusa entre O Príncipe e os Discorsi até porque os interesses dos príncipes quanto à estabilidade política não seriam diferentes dos governados. Maquiavel tende nos Discorsi a identificar a virtù já como compromisso definitivo com a coisa pública, sentindo atração pela ideia, abstrata e metafórica, de que o próprio Estado seja capaz de "virtù", de modo que também pode se corromper ${ }^{29}$.

Para uma compreensão mais distinta do percurso filosófico assumido por Maquiavel, conciliando os dois textos, O Príncipe e os Discursos, Mansfield argumenta que é necessário analisar a posição de Maquiavel diante de dois grandes desafios morais: refletir sobre se o homem, em razão de sua natureza, tem, necessariamente, compromisso com

25 Cf. O Príncipe, cap. II.

26 BARON, H. "Machiavelli: The Republican Citizen and the Author of The Prince". The English Historical Review, 76(299) (Apr. 1961), p. 217-253; p. 249-251. Skinner aceita a tese de Baron de que $O$ Príncipe foi escrito em alguns meses na segunda metade de 1513, enquanto os Discorsi teria sido iniciado em 1513, por incentivo dos membros dos Orti Oricellari, concluindo o trabalho por volta de 1519. Nenhum dos dois livros foi publicado enquanto Maquiavel estava vivo.

27 Harvey Mansfield contesta os malabarismos que tentam explicar as diferenças entre O Príncipe e os Discorsi. Para o professor americano tais diferenças teriam origem no método retórico de Maquiavel e na situação para a qual cada uma das obras foi concebida. MANSFIELD, H. The Machiavelli's virtue. p. 62.

${ }_{28}$ Maquiavel surge nesse ponto, para Skinner, como um revitalizador da tradição romana de considerar a liberdade como ausência de constrangimento, tanto para o indivíduo quanto para a república, mas de uma forma que o indivíduo preservaria sua liberdade natural mesmo quando devesse obedecer, em casos determinados, a regras impostas politicamente. Para compreender o embate sobre a fórmula da liberdade neorromana contra a liberdade entendida no estatismo contratualista do século XVII como liberdade permanentemente mediada pelas regras soberanas, cf. SKINNER, Q. Liberdade antes do liberalismo. São Paulo: Editora Unesp, 1998.

29 SKINNER, Q. As fundações do pensamento político moderno. op. cit. p. 196. 
o mal; e se a resposta tem a ver com a posição de um estrategista político ou se reflete um interesse da época que ele assumiu como verdadeira testemunha e exemplo de transição para a modernidade. Se o choque proveniente das repercussões da obra de Maquiavel consagrou o autor como um homem que assumiu o uso instrumental do mal tão conscientemente, como conciliar sua busca pela virtude num sentido antigo para o qual estava voltado com tanto tempo dedicado à história e aos modelos do passado? Se no começo dos Discorsi Maquiavel assume que tudo o que sempre fez foi pensando em trazer benefícios comuns a todos (Discursos, I), como entender que um professor de tal virtude num sentido novo (como em O Príncipe) possa ser ele mesmo virtuoso num sentido antigo?

Para um homem da renascença, mas também em franca oposição a ela, Maquiavel lidou com os desafios de conformar as virtudes públicas resgatando determinada antiguidade que forneceria o tônus intelectual propício para superar a atmosfera mental dominada pela teologia medieval. Com a busca de novas diretrizes o renascimento surge para Maquiavel como o convívio do antigo com o novo, mas a devoção pelo antigo é reinterpretada a todo tempo como um instrumento útil diante de cenários que são não apenas inéditos, mas intensamente mais complexos ${ }^{30}$.

Mansfield separa da obsessão de Maquiavel pelo novo o caráter de um artífice para quem o valor das melhores instituições se torna dúbio caso se entregue à rotina, incapaz de absorver os choques da história presente. Sua "modernidade" estaria no desafio de fazer com que a virtude dos antigos conviva com uma virtude baseada na mutabilidade incondicional e periódica do presente. A devoção aos romanos, para quem a política e a guerra eram virtudes supremas, em detrimento da sabedoria dos gregos decorria da ênfase com que aqueles investiam sobre os fundamentos de organização social do modo ativo e não contemplativo ${ }^{31}$. Maquiavel era, portanto, um homem inserido na longa tradição de pensadores dos assuntos políticos aos moldes romanos, mas, ao mesmo tempo, era um articulista interessado em renová-los de forma a tornar os meios antigos ainda mais eficazes do que foram, usando a seu favor a história e as premissas de um novo saber sobre o governo, tarefa a que ele dá início pela discussão sobre as habilidades imprescindíveis para o exercício do

30 Cf. POCOCK, J. G. A. "Machiavelli in the Liberal Cosmos". Political Theory, 13(4) (Nov. 1985), p. 559-574.

31 Exatamente por esse motivo a determinação de Maquiavel por considerar Tácito um autor mais importante do que Cícero. A própria instabilidade política vivida pelo autor de $O$ ano dos quatro imperadores guardava semelhanças profundas com a situação vivida em algumas cidades da península italiana. Cf. SUPPA, S. [A cura di]. Tacito e tacitism in Italia da Machiavelli a Vico. op. cit. 
poder. Dado o conteúdo da proposição, Mansfield afirma que não havia outro horizonte de referência para Maquiavel do que a filosofia moral de Aristóteles, nos moldes expostos na Ética a Nicômaco.

Ao contrário de Aristóteles, Maquiavel somente considerava a virtude na relação direta dos ganhos provindos dela, concentrando-se, sempre, na análise das condições reais para adquiri-la. A necessidade de adquirir os meios que levam à virtude pode obscurecer a ideia de que a virtude teria um fim em si mesma. Para Mansfield, a virtude moral em Aristóteles é cega a essa condição, e por isso ele teria discutido a aquisição da virtude na Política, e não na Ética a Nicômaco. A noção de virtude em Maquiavel estaria assim mais atenta a este fato, que pode ser conferido na confiança que nutre mantendo a necessidade como base de seu sistema-necessità fa virtù (Discursos, II, 12).

A necessidade, embora surja nos textos maquiavelianos ora como virtude, ora como independente da virtude é essencial em termos políticos porque impede a confiança na sucessão dinástica ou em quaisquer outros meios que estejam sujeitos a condições pré-estabelecidas às quais aquele que assume um novo posto se veja obrigado a obedecer. Como há uma relação de reciprocidade entre a virtude política e a natureza da coexistência social, o ingresso numa comunidade política significa também submissão aos meios que favorecem o desenvolvimento da virtude em cada um de seus habitantes e em seu governo. Para Maquiavel é melhor admitir, para longe da estática da forma política aristotélica, que, estando todas as coisas humanas em movimento, incluindo as repúblicas, elas movem-se de acordo com a necessidade, não de acordo com uma razão (ratio) pré-estabelecida. A razão não encontra na natureza formas eficazes para limitar a necessidade humana para adquirir, para conquistar, assim como as estruturas republicanas romanas não conseguiram conter o ímpeto para o crescimento imperial (Discursos, I, 6). Esse ímpeto, contudo, não é natural, ou seja, não é uma decorrência da naturalidade da forma política. O ímpeto para a expansão decorre da irrefreável condição humana. E pensando na vida em sociedade Il Principe é dedicado, como speculum do príncipe, não exatamente à busca da perfeição do soberano, mas ao aperfeiçoamento do relacionamento que este mantém com seus súditos e com outros políticos. A verdade da virtù não é apenas mostrada em seus efeitos, ela é o que seus efeitos são capazes de demonstrar. Se na concepção aristotélica existe a possibilidade de que um regime demonstre que é organizado em torno de certa virtude que pode ser entendida como uma virtude politizada, não se pode deixar de considerar que, nesse caso, ela está ancorada numa virtude prévia que Mansfield insiste que não é politizada. A maior consequência para Maquiavel é ter que abandonar a justiça como virtude 
particular, porque teria que ser compreendida (i) como virtude política e, consequentemente, (ii) porque teria que ser vista como um freio natural ao exercício da própria política. Maquiavel jamais se refere a direitos naturais ou justiça natural, tão comuns nos discursos filosóficos de sua época e tradições. A conclusão de Mansfield é que não se deve compreendê-lo como um homem de seu tempo, mas um innovator contra a renascença e, ao mesmo tempo, contra os antigos.

Inflexível com os rigores intelectuais, apesar de desafortunado na vida social, Maquiavel criticou a fragilidade com que seus compatriotas se esforçaram por passar da antiguidade para o presente, mediados pela vigilância ferrenha da Igreja. Maquiavel via a muitos escritores que ele mesmo admirava sob o constrangimento de fazer concessões semelhantes àquelas que autores antigos também se sentiram pressionados a fazer, simplesmente porque eram incapazes de fugir à debilidade do declínio histórico - como nos episódios que colocaram fim à república em Roma. Justamente em razão dessa revolta contra a fraqueza de sua época a doutrina da virtù de Maquiavel teve na necessidade do confronto com a fortuna seu tema mais relevante. Somente por meio de um necessário e inevitável processo contínuo de aquisição e acúmulo de poder seria possível se precaver contra a fortuna a ponto de não depender dela.

\section{A necessidade e a reformulação dos compromissos governamentais}

A avaliação de Mansfield sobre a ideia de necessidade em Maquiavel ganha contornos definitivos com aquilo que ele chama de "o começo em Maquiavel". Só haveria um motivo forte o bastante que pudesse ser caracterizado como essencial para a formação social na visão do pensador florentino: a necessidade. Herdeiros de Deus ou seres naturais, os homens surgiram no mundo limitados, desprotegidos, inseguros e justificadamente medroso ${ }^{32}$. A cada novo começo a epopeia dessas dificuldades é reatualizada, reencenada e novos combates são travados. Il Principe é um texto sobre um começo. Nos Discorsi, logo no primeiro livro, Maquiavel evoca a questão da relação entre a escolha e a necessidade, afirmando que onde as escolhas são menores maior é a virtude (Discursos, I, 1). O começo de toda sociedade política, seus atos fundadores, envolvem os fundadores num cenário vasto de obstáculos que estão na razão direta das suas incapacidades e despreparo. Não há uma estrutura original escondida aos olhos do fundador que seria preciso desvelar, conformando com suas atitudes o projeto de uma comunidade pré-organizada como

32 MANSFIELD, H. The Machiavelli's virtue, op. cit., p. 55. 
ideia. Num modelo ideal, o fundador de Maquiavel está livre para atuar, mas uma liberdade condicionada por suas limitações pessoais. Se Maquiavel busca a história para exemplificar esses momentos, ele sabe em Il Principe que não existe um plano ideal em que o novo príncipe encontre à sua disposição um principado absolutamente anômico e sem tradições, sem um passado que exerça pressão sobre suas escolhas, viciando o entendimento do povo acerca daquilo que deveria esperar de um novo governante (O Príncipe, 5). A fortuna do novo príncipe depende de todos esses elementos - normas estabelecidas, costumes tradicionais, vícios coletivos, etc. - , e é precisamente o fato de forçar a dependência do novo príncipe a esses elementos que incomoda Maquiavel. O novo príncipe, o innovator, deve ser capaz em primeiro lugar de levantar informações minuciosas sobre todos esses fatores que podem obstruir seu trabalho, e em segundo lugar ser capaz de avaliar qual a melhor forma de lidar com eles, de modo que lhe seja mais proveitoso para manter sua condição.

Pocock, lembrando o apelo aristotélico-tomista de Maquiavel ( $O$ Príncipe, capítulos 6 e 26) ${ }^{33}$, oferece uma visão sobre a relação entre a virtù do innovator e a fortuna diante do principado recém-conquistado medindo a imperatividade do domínio da deusa pela vontade do príncipe em termos de imposição da forma do príncipe sobre a matéria do principado. A função do príncipe como legislador seria impor a forma da politeia a constituição - sobre a matéria da politeuma, o corpo de cidadãos. A função da virtù é impor forma à fortuna ${ }^{34}$.

Ditar a forma sobre a matéria disponível não legitima, contudo, a pretensão de durabilidade sem fim da nova comunidade, por mais talentoso que seja o príncipe. A imortalidade secular não pode ser alcançada com um sistema permanente, institucionalizado e legitimado pelo uso e por uma nova tradição. O homem, no mundo das inovações, vive no presente. Dado um mundo que se vê e experimenta como ação e flutuação mais do que tradição e legitimidade, os sentimentos sobre

${ }^{33}$ Não só as relações estabelecidas entre Maquiavel e Aristóteles são alvo de intensas críticas à análise de Pocock, mas a insistência com que relaciona as mudanças republicanas no pensamento do florentino às premissas aristotélicas, mais do que às experiências da república romana. Cf. SULLIVAN, V. B. "Machiavelli's Momentary 'Machiavellian Moment': A Reconsideration of Pocock's Treatment of the Discourses". Political Theory, 20(2) (May 1992), p. 309-318.

34 "But when the subject is innovation, there is a pressing danger that virtù may deliver itself into fortuna 's power, and therefore the ideal type of innovator is he who depends as little as possible on circumstances beyond his control. The more the innovator is thought of as subverting and replacing a previously existing structure of custom and legitimacy, the more he will have to cope with the contingencies of suddenly disoriented behavior and the greater will be his exposure to fortuna." POCOCK, J. G. A. The Machiavellian moment. op. cit., p. 169. 
o presente são forçosamente mais fortes, a ação é mais excitante do que o costume, ela prende a atenção e excita as emoções ${ }^{35}$. Há um meio, entretanto, de restaurar uma visão diferente dessa abordagem que aproxima Maquiavel de alguns autores que exploraram seus textos no movimento geral do maquiavelismo, buscando uma equação que equilibrasse a natureza dos atos constitutivos da comunidade política e aqueles que são responsáveis pela sua manutenção. Mansfield associa essa questão ao problema maior da necessidade.

Nos Discorsi Maquiavel insiste que os atos fundadores de uma república, por mais violentos e imorais que sejam, podem ser escusados se sua finalidade buscar o bem comum da pátria em vez de erigir uma tirania pessoal. Nos primórdios de toda sociedade, aquele que se sente capaz e imbuído da tarefa de ordená-la se depara com enormes dificuldades e limitações decorrentes de sua incapacidade natural e de seu grupo. O principal objetivo do primeiro organizador social deverá ser corresponder a essas incapacidades tornando possível o controle político. Quando cita Alexandre buscando no Egito um local para construir a cidade que representaria sua glória e o esplendor de suas conquistas, o exemplo parece divinizar em demasia a extensão das preocupações de Alexandre, minimizando o caráter humano da empreitada. Mas Alexandre não escolhe o local para a construção de sua cidade seguindo os conselhos de seu arquiteto Dinócrates, que havia proposto erguê-la espetacularmente, com forma humana, sobre um monte, tarefa digna de um deus. Alexandre, tendo indagado seu arquiteto sobre se havia pensado em que condições se viveria nesse local, e obtendo resposta negativa, preferiu atender às necessidades de seus súditos, e edificou Alexandria onde seus habitantes pudessem morar próximos à fertilidade da terra e à comodidade do mar e do Nilo (Discursos, I, 1). O primeiro fator, portanto, a consagrar um grande fundador é a escolha do local onde será a cidade. E em segundo lugar Maquiavel determina a capacidade de ordenar as leis.

A esterilidade e a aridez desafiam a capacidade de escolha dos fundadores, que devem se lembrar que, por mais virtuosos que sejam, não podem ignorar, como se fossem deuses, seus próprios limites. Não adianta construir suntuosas e belas cidades que não satisfaçam os requisitos básicos de sobrevivência exigíveis para que a vida humana seja viável - e o principal deles é evitar a dominação por outros. É necessário evitar tal esterilidade, e buscar locais férteis onde a vida possa ser mais agradável e protegida. E seria ideal se ela pudesse se desenvolver assim, se cada um pudesse viver sua própria vida sem desejar comandar os

35 POCOCK, J. G. A. The Machiavellian moment. op. cit., p. 179. 
outros, mas como isso não é possível, escolher bem o local da cidade é escolher, nos termos colocados por Mansfield, "a próxima vítima" - quem não comanda é comandado ${ }^{36}$. Aquilo que parecia ser uma escolha livre o ato fundador - é restrito a uma escolha entre necessidades e decidido pela necessidade soberana - o desejo humano de comandar os outros. Onde outros autores viram no começo das cidades a presença divina, Maquiavel encontrou o poder e a virtude da necessidade. Desde que os homens - prossegue Mansfield -, são independentes da divindade por causa de suas necessidades, eles devem decidir independentemente e de acordo com suas necessidades. Os homens são independentes da divindade, mas não estão livres para decidir de acordo com seus próprios desejos. Devem medir suas forças e calcular como usar bem a sua liberdade possível.

\section{As reservas fundadoras do poder}

A lição exposta por Maquiavel possui uma conclusão bastante simples: as leis nascem da necessidade de impor a ordem e de comandar os homens. São feitas para a necessidade da segurança e por causa da segurança ${ }^{37}$. Preocupado em estabelecer a diferença entre as necessidades humanas e as divinas no primeiro capítulo dos Discorsi, a interpretação de Maquiavel para o começo das repúblicas não responde ao questionamento sobre o peso que os modelos antigos têm para os novos fundadores nos sete capítulos seguintes do texto. O novo começo de uma cidade, argumenta Mansfield, diferente do exemplo antigo, precisa ser reenviado do puramente humano para o divino, ou extraordinário. No nono capítulo Maquiavel usa expressões como "ordinatore" e "fondatore" para ressaltar a característica heroica, quase religiosa, daqueles que conseguem sobrepor os obstáculos para ordenar uma nova república e dar a ela a forma de sua vontade. A necessidade força os fundadores a perseguir o novo, e a necessidade de segurança acaba por implicar a necessidade de conquista (acquiring), para se proteger e evitar ser dominado ${ }^{38}$. Novos fundadores, contudo, pela natureza dos atos a que são levados a cometer, podem ser vistos como arrogantes e temíveis, e para evitar o temor social precisam esconder seus atos por meio da religião que

MANSFIELD, H. The Machiavelli's virtue. op. cit., p. 70.

37 "Aristotle explained that the reason for the coming-into-being of a polis is not the same as its reason for staying-in-being; men come together to protect life and stay together for the sake of the good life. According to Machiavelli, however, protection is the first and last goal of cities. He implies here what he argues amply elsewhere, that the danger of civilized enemies is as great and as fearful as the pressure of elementary necessities". MANSFIELD, H. The Machiavelli's virtue. op. cit., p. 71.

38 MANSFIELD, H. The Machiavelli's virtue. op. cit., p. 75. 
dá sentido superior às ações que a maioria não poderia entender. Como os homens mais louváveis são os ordenadores das religiões (Discursos, I, 10), o novo governante deve mascarar a violência fundadora sob o manto das boas finalidades ${ }^{39}$. Suas escolhas são refletidas como atitudes altruístas e formadoras de consenso social, e os governados aceitam se submeter porque necessitam das consequências advindas da coragem dos fundadores. Maquiavel argumenta um começo para as cidades fundado nas necessidades humanas, que omite a primeira necessidade - e a primeira necessidade do começo (principio) é um príncipe que faz tudo novo ${ }^{40}$.

Esse novo princípio - seguindo o raciocínio de Maquiavel no capítulo 10 dos Discorsi - não é, necessariamente, o meio pelo qual haverá de ser mantida a república. O começo determinado pelo grande ordinatore desaparece no seu governo enquanto procura se pautar pela prudência e pela virtù. O começo é escusável em função dos fins, mas, a partir desse primeiro momento, o governo deve seguir a virtude. No caso de Rômulo, o melhor exemplo para escusá-lo foi a constituição do Senado para auxiliá-lo nas deliberações - e o fato de ter reservado para si apenas o poder para comandar as tropas em caso de guerra e o poder de reunir o Senado (Discursos, I, 9). Para ordenar uma república é necessário estar só, completa Maquiavel - decorrendo desta constatação toda a carga de significados que remontam à livre disposição da vontade do fundador para agir sem freios. Para mantê-la, o fundador deve abrir mão da totalidade desse poder e compartilhá-lo, preservando uma parte dele para certas ocasiões. Assim, o fundador apenas consegue realizar o ordinário recorrendo ao extraordinário ${ }^{41}$.

O recurso a fontes extraordinárias de poder será mais tarde um dos núcleos constitutivos da ideia eminentemente moderna de razão de Estado que muitos atribuíram a Maquiavel - a preservação da ordem pública depende da possibilidade aberta de utilização de um poder reservado, original, que, quando liberto, age sem freios e é justificado apenas na razão de seus fins. É em face desse conturbado ambiente de pressões sociais já bastante antigas e pouco suscetíveis a modificações que os instrumentos ensinados por Maquiavel para o exercício do poder provocaram tantas reações, positivas e negativas, dando origem a um conjunto de ideias que se confundem, em termos teóricos e práticos, com os fundamentos da forma nascente do estado.

\footnotetext{
39 No cap. 11 do livro I, porém, a ênfase de Maquiavel é mais para a importância da religião como manutenção da república do que para a fundação. A religião é instrumento útil para conduzir o respeito às leis e a garantia da ordem.

40 MANSFIELD, H. The Machiavelli's virtue. op. cit., p. 77.

41 A frase é de Mansfield. MANSFIELD, H. The Machiavelli's virtue. op. cit., p. 325.
} 
O confronto entre o texto de Maquiavel e a carreira teórica e política do maquiavelismo ainda é tema de intensas discussões acadêmicas. Não há boas evidências para defender que Maquiavel tenha organizado seu trabalho com a finalidade de teorizar sobre o estado. Mesmo a consciência histórica que tinha de seu presente é questionável. Sua conhecida militância para organizar uma tropa local em Florença destoa do movimento geral de formação dos grandes exércitos modernos, e seu clamor pela unificação civil da Itália desconsiderou a importância do laço de legitimidade que ainda iria manter entidades como o Sacro-Império e grandes reinos como a França e a Espanha no controle das ações geopolíticas da Europa por um bom tempo ${ }^{42}$. Embora tenha visto pouco das lutas da Contra-Reforma, Maquiavel não parece ter compreendido o quanto a defesa que fizera de um uso instrumental da religião pelo poder político viria a abalar os fundamentos das estruturas medievais, contra as quais escrevia.

Apesar disso, é inquestionável que os fundamentoas éticos da revolução que viria a dominar a Europa central já estavam, quase que integralmente, sendo objeto de suas preocupações. Em pouco tempo, seu trabalho provocaria na França acirrados debates intelectuais e políticos, estabelecendo os parâmetros para reformas sem volta. O próprio fenômeno do secularismo e do laicismo, ancorados no discurso da tolerância civil, tem nos textos de Maquiavel uma insuspeita base sólida - não foi por outro motivo que o pensador florentino cativou intelectuais como Jean Bodin ou Justus Lipsius ${ }^{43}$. Os detratores de Maquiavel se contam em número equivalente ao de seus defensores, inclusive entre os protestantes da seita dos politiques, os quais sustentavam a badeira da tolerância perante um trono católico. Montaigne irá retomar a discussão sobre a natureza ética da virtude privada em submissão aos imperativos da utilidade instrumental pública, e Lipsius fará o mesmo, mais tarde, ambos fugindo das consequências do caos que se instalou no ambiente das guerras de religião do século XVI - ambos, como muitos outros, enfrentando desafios semelhantes àqueles expostos pelo pensamento do controvertido autor florentino.

Penso que a maior virtude do trabalho de Maquiavel foi recriar certo sentido da noção de poder público desde muito esquecida; mas é preciso

42 A esse respeito Federico Chabod afirma que apesar dos apelos patrióticos entre intelectuais renascentistas, durante o século XVI as decisões políticas de cada ente continuariam, em sua maioria, unilaterais, sobretudo no cenário das guerras da reforma, mantendo o "furor religioso" muito acima do "furor nacional". Cf. Escritos sobre el Renacimiento, p. 529.

43 Sobre o fenômeno do maquiavelismo e a extensão dos debates que dominaram as lutas polítcas do século XVI e parte do século XVII, conferir o artigo que publiquei nos Cadernos de Ética e Filosofia Política da USP, n. 25, Considerações filosóficas sobre a leitura e divulgação de "O príncipe" no início da modernidade. 
reconhecer que o passo primordial para que esse trabalho fosse adiante - a conceituação nítida de estado - não poderia ter sido dado por ele. Por outro lado, a conceituação da forma do estado dependeu das discussões éticas sobre a razão de estado numa relação causal direta. Ao contrário do que defendeu Gaines Post ${ }^{44}$, o sentido de poder público de que os teóricos da razão de estado precisavam para enunciar o estado não poderia vir dos autores medievais, imersos nas reflexões de uma vida privada, como demonstrado por Pocock. Essa transformação dependeu do trabalho de Maquiavel para se desenvolver, consolidando uma definitiva transição intelectual para a modernidade política.

\section{Referências}

BARCIA, Franco. Tacito e tacitismi in Italia tra Cinquecento e Seiscento. In: SUPPA, Silvio. "Tacito e tacitismi in Italia da Machiavelli a Vico". Teoria e storia della ragion di Stato, Napoli: Archivio della Ragion di Stato - Adarte, Quaderno 3 (2003), p. 43-58.

BARON, H. A "Struggle for Liberty in the Renaissance: Florence, Venice, and Milan in the Early Quattrocento (Part one)". The American Historical Review, 58(2) (Jan. 1953), p. 265-289.

. "A Struggle for Liberty in the Renaissance: Florence, Venice, and Milan in the Early Quattrocento (Part two)". The American Historical Review, 58(3) (Apr. 1953), p. 544-570.

"Machiavelli: The Republican Citizen and the Author of The Prince". The

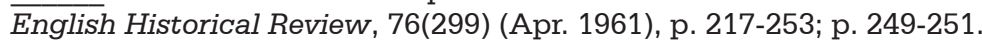

BOCK, G.; SKINNER, Q.; VIROLI, M. Machiavelli and republicanism. Cambridge: Cambridge University Press, 1993.

BORRELI, G. Ragion di Stato e leviatano - conservazione e scambio alle origini della modernità politica. Bolonha: Il Mulino, 1993.

. [A cura di]. "Prudenza civile, bene comune, guerra giusta. Percorsi della ragion di Stato tra seicento e settecento". Teoria e storia della ragion di Stato, Napoli: Archivio della Ragion di Stato - Adarte, Quaderno 1 (1999).

. [A cura di]. "Machiavelli e la cultura politica del meridione d'Italia". Teoria e storia della ragion di Stato, Napoli: Archivio della Ragion di Stato - Adarte, Quaderno 2 (2001).

CHABOD, F. Escritos sobre el Renacimiento. Mexico: Fondo de Cultura Ecónomica, 1990.

COLISH, M. "Cicero's De Officiis and Machiavelli's Prince". Sixteenth Century Journal, Central Renaissance Conference, 9(4) (Winter 1978), p. 80-93.

DIONISOTTI, C. Machiavelleire. Torino: Einaudi Editore, 1980.

DONALDSON, P. S. Machiavelli and mystery of state. Cambridge: Cambridge University Press, 1988.

44 POST, Gaines. Studies in Medieval Legal Thought - Public law and the State, 110-1322. Princeton: Princeton University Press, 1964. Conferir a parte 2, Public law and the State, V: Ratio publicae utilitas, ratio status et "raison d'État": 1100-1300. p. 241-310. 
R. Jacarandá - Os pressupostos filosóficos do maquiavelismo ...

FIRPO, L. Scritti sul pensiero politico del Rinascimento e della Controriforma. Torino: Utet Libreria, 2005.

FOUCAULT, M. Securité, territoire et population. Cours au Collège de France (19771978). Édition établie sous la direction de François Ewald et Alessandro Fontana, par Michel Senellart. Paris: Gallimard, Seuil, 2004.

GILBERT, F. The humanist conception of the Prince and The Prince of Machiavelli". The Journal of Modern History, 11(4) (Dec. 1939), p. 449-483, p. 479.

. The Concept of Nationalism in Machiavelli's Prince. Studies in the renaissance, Vol. 1. [Published by Renaissance Society of America.] (1954), p. 38-48.

. “On Machiavelli's Idea of Virtu". Renaissance News, 4(4) (Winter, 1951).

GUICCIARDINI, F. Dialogo del reggimento di Firenzi. p. 230-231. A cura de Gian Mario Anselmi e Carlo Varotti. Bollati Boringhieri: Torino, (1994) 2006.

. Se sia lecito condurre el populo alle buone legge con la forza non potendo farsi altrimenti. In: Scritti politici e Ricordi. Collezione: Scrittori d'Italia. Bari: G. Laterza Editore, 1933 [Edição eletrônica de 2000].

LAZZERI, C. ; REYNIÉ, D. (Org.). La raison d'État : politique et rationalité. Paris: Presses Universitaires de France, 1992.

MANSFIELD, H. The Machiavelli's virtue. Chicago: The Chicago University Press, 1996.

MAQUIAVEL, N. Il Principe (De principatibus) Edizione a cura de Luigi Firpo. Torino: Einaudi Editore, 1972.

. Discorsi sopra la prima deca de Tito Livio. Tutte le Opere de Niccolò Machiavelli. $\bar{A}$ cura de Mario Martelli. Firenze: Sansoni Editore, 1971.

1996.

. O Príncipe. Tradução Maria Júlia Goldwasser. São Paulo: Martins Fontes,

Discursos sobre a primeira década de Tito Lívio. Tradução MF. São Paulo: Martins Fontes, 2007.

MATTEI, R. De. Il problema della "ragion di Stato " nell'Età della controriforma. Milano - Napoli: Riccardo Ricciardi Editore, 1979.

MEINECKE, F. L'idée de la raison d'État dans l'histoire des temps modernes. Traduit de l'allemand par Maurice Chevallier. Geneva: DROZ, 1973.

MESNARD, P. L'essor de la philosophie politique au XVI ${ }^{e}$ siècle. 3. éd. Paris: Vrin, 1977.

MINDLE, G. B. “Machiavelli's Realism”. The Review of Politics, 47(2) (Apr. 1985), p. 212-230.

POCOCK, J.G.A. The Machiavellian moment - Florentine Political thought and the Atlantic republican tradition. Princeton and Oxford: Princeton University Press, [1975] 2003. p. 559-574.

"Machiavelli in the Liberal Cosmos". Political Theory, 13(4) (Nov. 1985),

POST, G. Studies in Medieval Legal Thought - Public law and the State, 110-1322. Princeton: Princeton University Press, 1964.

QUARTIM DE MORAES, J. A justificação do tiranicídio no pensamento proto-liberal de Juan de Mariana. Coleção Primeira Versão, IFCH/UNICAMP. Campinas: IFCH/ UNICAMP, 1993. p. 12. 
R. Jacarandá - Os pressupostos filosóficos do maquiavelismo ...

RIDOLFI, R. Biografia de Nicolau Maquiavel. São Paulo: Musa Editora, 2003.

SARUBBI, A.; SCUDIERI, P. I teorici della ragion di Stato - Mito e realtà. Napoli: Edizione Scientifiche Italiane, 2000.

SCATTOLA, M. Teologia politica. Collezione Lessico della politica. Bologna: Il Mulino, 2007.

SENELLART, M. Machiavélisme et raison d'État - XII $-\mathrm{XVIII}{ }^{\mathrm{e}}$ siècle. Paris: Presses Universitaire de France, 1989.

SENELLART, M.; SFEZ, G.. L'enjeu Machiavel. Paris: Presses Universitaires de France, 2001.

SKINNER, Q. Maquiavel . Tradução de Maria Lúcia Montes. São Paulo: Ed. Brasiliense, 1988.

. As fundações do pensamento político moderno. São Paulo: Martins fontes, 1996.

Liberdade antes do liberalismo. São Paulo: Editora Unesp, 1998.

STOLLEIS, M. Stato e ragion di stato nella prima età moderna. Collezione di testi e di studi. Bolonha: Il Mulino, 1998.

SULLIVAN, V. B. “Machiavelli's Momentary 'Machiavellian Moment': A Reconsideration of Pocock's Treatment of the Discourses". Political Theory, 20(2) (May 1992), p. 309-318.

SUPPA, S. [A cura di]. Tacito e tacitism in Italia da Machiavelli a Vico. Teoria e storia della ragion di Stato, Napoli: Archivio della Ragion di Stato - Adarte, Quaderno 3 (2003).

THUAU, E. Raison d'État et pensée politique à l'époque de Richelieu. Paris: Albin Michel, [1966] 2000.

VASOLI, C. Machiavel inventeur de la raison d'État? In: ZARKA, Yves Charles (Org.). Raison e déraison d'État. Théoriciens et théories de la raison d'État aux XVI ${ }^{\mathrm{e}}$ et XVII siècles. Paris: Presses Universitaires de France, 1994.

VIROLI, M. Dalla politica alla ragion di Stato - La scienza del governo tra XIII e XVII secolo. Roma: Donzelli Editore, 1994.

. O sorriso de Maquiavel : história de Maquiavel. Tradução de Valéria Pereira da Silva. São Paulo: Estação Liberdade, 2002.

. "The Revolution in the Concept of Politics". Political Theory, 20(3) (Aug. 1992), p. 473-495.

WHITFIELD, J. H. "The Politics of Machiavelli". The Modern Language Review, 50(4) (Oct. 1955), p. 433-443.

ZARKA, Y. C. Crise et réappropriation discursive: l'usage de l'aristotélisme dans les traités de la raison d'État. In: BALDINI, Enzo (Org.). Aristotelismo politico e ragion di Stato. Atti del convegno internazionale di Torino, 11-13 febbraio 1993. Firenze: Leo S. Olschki Editore, 1995.

\section{Endereço postal:}

Departamento de Filosofia

Largo de São Francisco de Paula 1

Rio de Janeiro, RJ, Brasil

Data de recebimento: 31/02/2014

Data de aceite: 15/01/2016 